\title{
Demand side management analysis of a commercial water loop heat pump system
}

\author{
Gianluca Coccia $^{1 *}$, Alessia Arteconi ${ }^{2}$, Paola D’Agaro ${ }^{3}$, Fabio Polonara ${ }^{1,4}$, Giovanni Cortella $^{3}$ \\ ${ }^{1}$ Università Politecnica delle Marche, Department of Industrial Engineering and Mathematical Sciences, via Brecce Bianche \\ 12, Ancona (AN) 60131, Italy \\ ${ }^{2}$ Università eCampus, via Isimbardi 10, Novedrate (CO) 22060, Italy \\ ${ }^{3}$ Università di Udine, Polytechnic Department of Engineering and Architecture, via delle Scienze 206, Udine (UD) 33100, \\ Italy \\ ${ }^{4}$ Consiglio Nazionale delle Ricerche, Construction Technologies Institute, Viale Lombardia 49, San Giuliano Milanese, (MI) \\ 20098, Italy
}

Corresponding Author Email: g.coccia@ univpm.it

https://doi.org/10.18280/mmc_c. 790308

Received: 21 March 2018

Accepted: 29 May 2018

\section{Keywords:}

DSM, real-time pricing, water loop, heat pump, thermal storage

\begin{abstract}
Demand side management (DSM) strategies can be used to reduce customers' demand at peak times, change the timing of end-use consumption from high to low-cost periods and increase consumption during off-peak periods. They can be implemented by using the energy flexibility available in the final users' applications, energy storages or control systems to turn on/off end-users' devices when required. Being intensive energy consumers because of a high electric energy demand (refrigeration accounts for about $40 \%$ of the yearly energy consumption), supermarkets are ideal candidates for a DSM approach. This work shows the results of a DSM analysis carried out for a refrigeration and HVAC plant in a supermarket coupled with a Water Loop Heat Pump (WLHP) system. The water loop is used as a heat source/sink for the refrigeration unit supplying the cooling capacity required by food preservation, and for several heat pumps, which provide heating/cooling inside the supermarket building. The system is modelled in TRNSYS and the role of the water loop and its thermal inertia to provide energy flexibility is investigated. The system design and control strategy are modified in order to reduce the electricity costs in presence of demand response programs based on real-time price mechanisms.
\end{abstract}

\section{INTRODUCTION}

The penetration of renewable energy sources in the generation mix is increasing in the European countries thanks to the Renewable Energy Directive, which sets a target of at least $20 \%$ of electricity produced from renewable sources by 2020. Thus, all European countries have adopted appropriate sustainable energy policies. Because of the great diffusion of small and medium renewable energy plants, there is a need for a complete revision of planning and management criteria of the electricity grid. Given the low predictability of renewable sources, one of the biggest challenge of the future is to increase the flexibility of energy networks to improve the reliability of the entire energy system and to make competitive the price of energy. As Lund et al. [1] observed, several solutions could be adopted for this purpose: energy storages, demand side management (DSM), flexible conventional power plants or investments in the modernization of the electricity grid infrastructure. Among these, one of the most interesting solutions is DSM. DSM contains all those policies that aim to influence the customer's energy curve, focusing on changing the shape of the load and thereby helping to optimize the whole power system from generation to delivery, to end use [2]. One of the various DSM strategies is Demand Response (DR). It refers to changes in electricity use of end customers from their normal consumption patterns in response to changes in the electricity price over time [3].

Nowadays, there is a growing interest towards the application of demand side management (DSM) strategies in the refrigeration sector due to the incidence on the overall energy consumption of refrigeration technologies. The International Institute of Refrigeration estimates that the total number of refrigeration, air-conditioning and heat pump systems in operation worldwide is roughly 3 billion units and the refrigeration sector consumes about $17 \%$ of the overall electricity used worldwide [4]. Considering the different sectors where refrigeration technologies can be applied, some average data about the worldwide electricity demand are provided in [4]. For example, in supermarkets $45 \%$ of the electric energy is used to cool cabinets and cold rooms for food storage, while household refrigerators and freezers consume almost $4 \%$ of residential electricity demand. In the latter sector, while the efficiency of the devices is growing, the number of units has been increasing constantly. Air conditioners, instead, are responsible for an average of around $5 \%$ of global electricity consumption, with a variable percentage country by country (e.g., $14 \%$ in US and $40 \%$ in India). The relevance of heat pumps is also increasing, in 2015 about 800,000 units were sold in EU-21 and they make possible a $50 \%$ reduction of the building sector's $\mathrm{CO}_{2}$ emissions [4]. Thus, the refrigeration sector needs to be accurately investigated to look for energy reduction and energy management strategies [5].

Among the systems used in the refrigeration sector to reduce energy consumption, the Water Loop Heat Pump (WLHP) system was introduced years ago to take advantage 
of both distributed heating/cooling generation with local control and low condensing temperature. The arrangement consists of a water loop acting simultaneously as sink/source for several reversible water/air heat pumps, each one serving a confined space autonomously $[6,7,8]$. The temperature of the water loop is the effect of the energy balance between all the heat pumps which are operating in cooling/heating mode. The most effective operation occurs when the two operating modes are balanced, which could happen in the mid seasons or when some zones require heating or cooling throughout all the year.

Thanks to its significant thermal inertia, a WLHP system could be used as a thermal energy storage (TES) to change the timing of end-use consumption from high-cost periods to lowcost periods, and increase consumption during off-peak periods [9]. In fact, during off-peak times, heating or cooling can be generated by electricity, stored in the WLHP system as sensible heat of water and then used during peak-hours to flatten the utilities' load profile. A similar application could lead to a more efficient system and to economic savings if the system takes advantage of the different electricity prices during peak and off-peak hours.

The purpose of this work is to illustrate the potential for DSM of refrigeration technologies, in the specific case of a supermarket where a WLHP system is integrated with the refrigeration system.

\section{REFRIGERATION UNIT AND WLHP SETUPS}

The plant configuration of the supermarket is depicted in

Figure 1. It consists of two parts: a WLHP system, where several heat pumps provide climate control on the building thermal zones, and a commercial refrigeration unit (CRU) with auxiliary compression and an additional high-pressure heat exchanger ( $\mathrm{HX}$ in

Figure 1) for heat recovery purposes in favor of the WLHP. The heat pumps adopt the hydrofluoroolefin R1234ze(E) as low-GWP working fluid, while the refrigeration unit consists of a $\mathrm{CO}_{2}$ transcritical booster system.

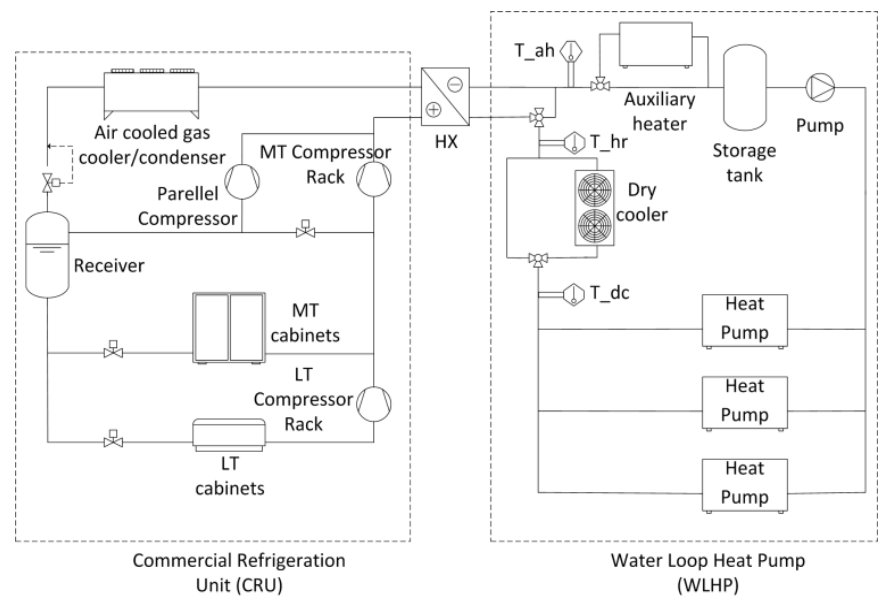

Figure 1. Plant configuration

In the heating season, heat from the de-superheating process of $\mathrm{CO}_{2}$ is transferred to the water loop through the highpressure heat exchanger. When the amount of heat available from the refrigeration system is low, the water loop temperature can be increased by means of an air-to-water heat pump (auxiliary heater). In wintertime, the water loop represents a source for the water-to-water/air heat pumps, and its temperature is a crucial factor in the operation of the whole system. In fact, high temperature values favor the heat pumps but are of detriment for the refrigeration plant which could take advantage of the low external temperature [10].

In the cooling season, instead, the heat pumps operate for air conditioning and a dry cooler on the water loop allows heat rejection to the environment, as the water loop temperature should be as low as possible.

The mass flow rate in the loop is constant throughout the year, its value being the sum of the mass flow rates required by the heat pumps. A water tank is also provided as thermal storage, with the purpose of shaving peaks and reduce the intervention of the auxiliary heater or the dry cooler.

\section{ENERGY DEMAND PROFILES}

The plant was designed for a food store of $6352 \mathrm{~m}^{2}$ vending area and the annexed warehouses, services and hallways for other eleven thermal zones $\left(5411 \mathrm{~m}^{2}\right)$. The supermarket is located at the ground floor of a larger modern shopping mall.

The building was simulated in TRNSYS [11] in order to assess the cooling and heating demands of the thermal zones. The total cooling capacity at rated conditions of each display cabinet was adjusted considering realistic and time-dependent working conditions in a supermarket [12], while the influence of indoor air temperature and humidity on the sensible and latent fractions of the cooling load were considered as well as the time schedule for the auxiliary devices [13]. Other details on the assumptions made in the definition of the thermal loads can be found in [10].

\subsection{Heating, cooling and DHW demands}

In this study, a location characterized by mild climate conditions (Milan, Italy) was considered. The weather files were extrapolated by Meteonorm [14] from data collected from 2000 to 2009 (Table 1).

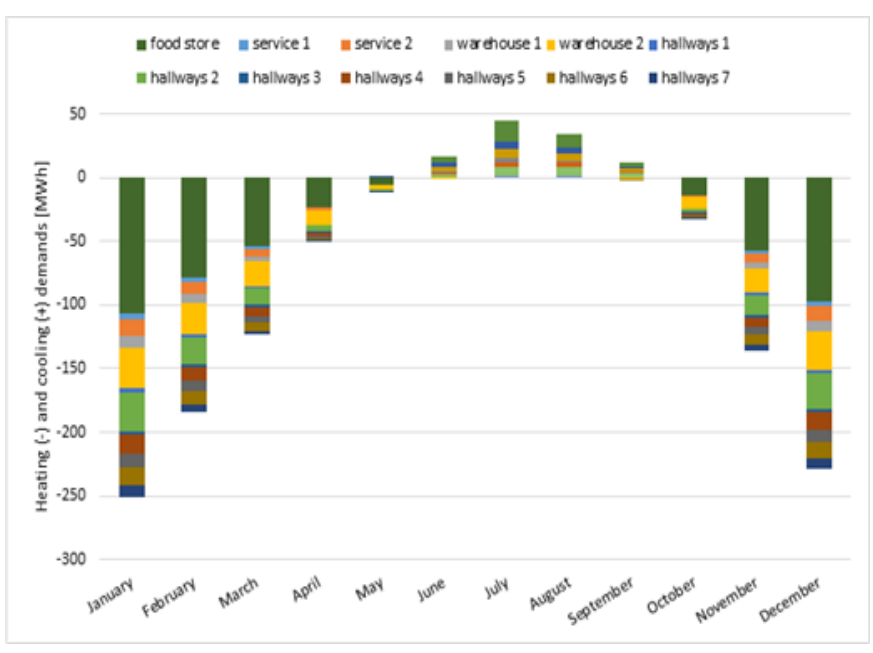

Figure 2. Heating/cooling demands for the thermal zones

Table 1. Climate conditions

\begin{tabular}{cc}
\hline Climate condition & Value \\
\hline Annual average temperature $\left[{ }^{\circ} \mathrm{C}\right]$ & 11.6 \\
\hline Average annual temperature fluctuation $\left[{ }^{\circ} \mathrm{C}\right]$ & 22.2 \\
\hline Maximum daily temperature fluctuation $\left[{ }^{\circ} \mathrm{C}\right]$ & 23.7 \\
\hline Heating degree days [HDD/year] & 2404 \\
\hline
\end{tabular}


The monthly heating and cooling demands of the various thermal zones are detailed in

Figure 2 (the heating demand is represented with a negative value, while the cooling demand is depicted with a positive value).

The thermal zones show either a heating or a cooling demand for most of the year except in May, when two hallways, due to their orientation, have a small cooling request, and in June and September, when the warehouse hosting the cold rooms has a heating demand.

The domestic hot water usage is estimated at a maximum value of $0.250 \mathrm{~m}^{3}$ per hour during the opening hours.

\subsection{Refrigeration demand}

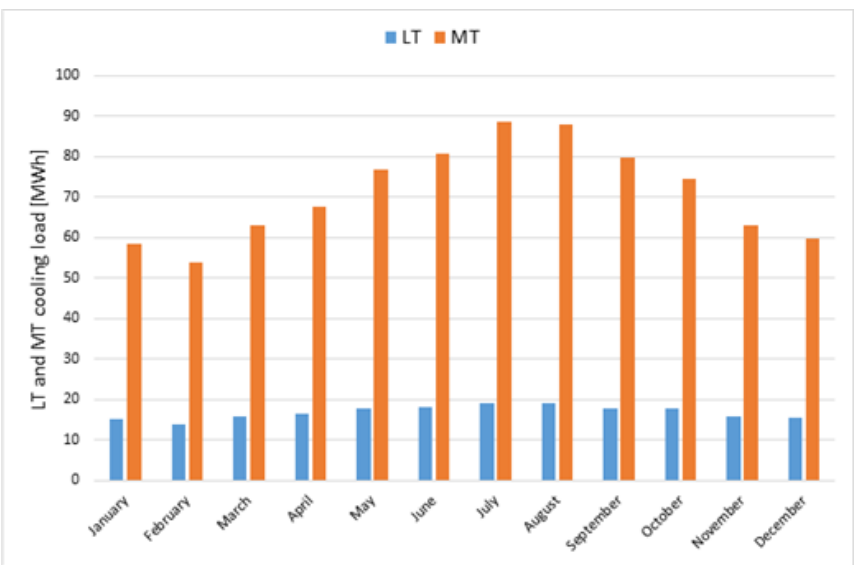

Figure 3. Cooling load of the refrigeration system

The food store is composed of refrigerated display cabinets for a total length of $208 \mathrm{~m}$ and 10 cold rooms at medium temperature (MT), and frozen food display cases for a total length of $86 \mathrm{~m}$ and 2 cold rooms at low temperature (LT). The refrigeration plant has a MT capacity of $140 \mathrm{~kW}$ (evaporative level fixed at $-8{ }^{\circ} \mathrm{C}$ ) and a LT capacity of $28 \mathrm{~kW}$ (evaporative level fixed at $-35^{\circ} \mathrm{C}$ ). The cooling load profile is evaluated based on a detailed simulation of the display cabinets and their interaction with the indoor ambient [12]. The monthly values of cooling load are reported in

Figure 3.

\section{SYSTEM MODEL}

The mathematical models of both the refrigeration unit and the WLHP system were developed in TRNSYS. The following sections describe each component in detail.

\subsection{Commercial refrigeration unit}

Table 2. Design parameters of the refrigeration unit

\begin{tabular}{cc}
\hline Parameter & Value \\
\hline LT Evaporating temperature $\left[{ }^{\circ} \mathrm{C}\right]$ & -35 \\
\hline MT Evaporating temperature $\left[{ }^{\circ} \mathrm{C}\right]$ & -8 \\
\hline Superheating at evaporators $[\mathrm{K}]$ & 5 \\
\hline Superheating in the suction lines $[\mathrm{K}]$ & 5 \\
\hline$\Delta \mathrm{T}$ approach of the condenser/gas cooler $[\mathrm{K}]$ & 3 \\
\hline Minimum condensing temperature $\left[{ }^{\circ} \mathrm{C}\right]$ & 8 \\
\hline Liquid receiver pressure (in subcritical operation) & 3.8 \\
\hline$\Delta \mathrm{MPa}]$ & 5 \\
\hline
\end{tabular}

For the $\mathrm{CO}_{2}$ transcritical booster system with auxiliary compression, BITZER Software [15] was used to define the global efficiencies of the compressors as a function of the pressure ratio, while the thermodynamic properties were obtained through CoolProp libraries [16]. The values of the main design parameters considered for the commercial refrigeration unit are provided in Table 2.

The $\mathrm{CO}_{2}$ refrigeration system operational mode (subcritical, transition or trans-critical) depends on the ambient temperature and the corresponding percent time subdivision is reported in Table 3.

Table 3. Operational mode ( $\%$ time) of the refrigeration unit

\begin{tabular}{cc}
\hline Mode & Value [\%] \\
\hline Subcritical & 81 \\
Transition & 14 \\
Trans-critical & 5 \\
\hline
\end{tabular}

\subsection{Heat pumps}

The vapor compression cycles of the heat pumps were implemented in TRNSYS linked to CoolProp libraries. The global efficiencies of the compressors, instead, were obtained as a function of the pressure ratio by using Frascold Software [17]. The values of the main design parameters considered for the heat pumps are reported in Table 4

Table 4. Design parameters of the heat pumps

\begin{tabular}{cc}
\hline Parameter & Value \\
\hline Useful superheating [K] & 4 \\
\hline Superheating in the suction lines [K] & 4 \\
\hline Subcooling in heating mode [K] & 3 \\
\hline Subcooling in cooling mode [K] & 2 \\
\hline Approach temperature of the source heat exchanger $[\mathrm{K}]$ & 5 \\
\hline Approach temperature of the load heat exchanger $[\mathrm{K}]$ & 5 \\
\hline Minimum condensing temperature in cooling mode $\left[{ }^{\circ} \mathrm{C}\right]$ & 25 \\
\hline
\end{tabular}

Correlations to estimate the COP and the EER of the heat pumps were determined as a function of the evaporating and condensing temperatures, respectively; further details are provided in [10].

\section{DSM ANALYSIS AND RESULTS}

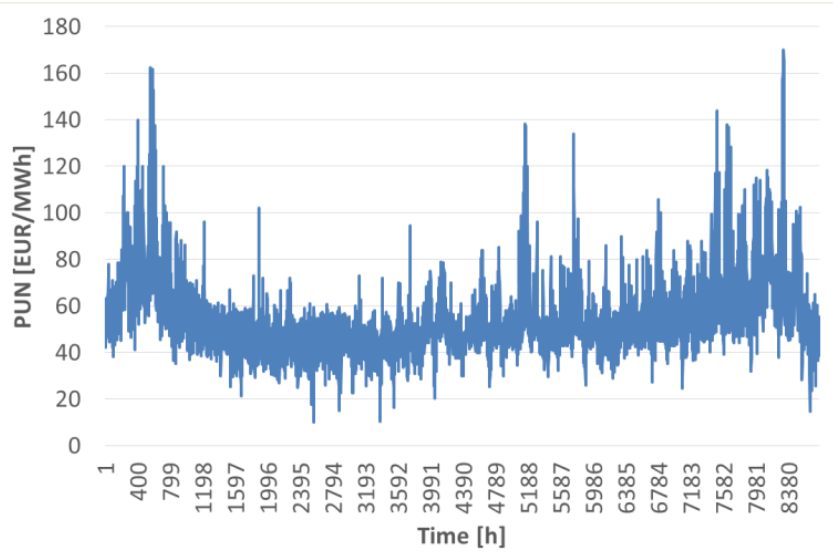

Figure 4. Italian PUN in 2017 
The DSM strategy applied to the proposed WLHP system aims to minimize the yearly electric energy cost by taking advantage of the thermal inertia of the water loop. It is assumed that the supermarket adheres to a demand response (DR) program based on real-time pricing (RTP) [18].

Since the proposed work was carried out for a supermarket located in Italy, the Italian PUN (National Single Price) referred to 2017 was considered as real-time price applied to the customer. The PUN represents the electric energy reference price observed on the Italian Power Exchange and has a time resolution of one hour [19].

Figure 4 shows the trend of the Italian PUN in 2017.

Given the hourly resolution of the PUN, the DSM analysis was carried out by adjusting, for each hour of the yearly simulation, the temperature set-points that regulate the WLHP operation. Once the water return temperature is determined, the heat recovery from the refrigeration unit and the auxiliary devices of the water loop are activated according to the following control strategy (Figure 1):

(1) when the water temperature drops below a heat recovery set-point temperature $\left(T_{\mathrm{hr}}\right)$, the heat recovery from the refrigeration unit is activated;

(2) when the water temperature drops below a second heating set-point temperature $\left(T_{\mathrm{ah}}<T_{\mathrm{hr}}\right)$, the auxiliary heater is activated;

(3) when the water temperature rises to a cooling set-point temperature $\left(T_{\mathrm{dc}}\right)$, the dry-cooler is activated to cool the water loop in accordance with the outdoor temperature and the drycooler approach temperature.

In this work, the initial WLHP configuration (referred to as baseline) adopted the set-points provided in Table 5. In the same table, the default volume of the water reservoir was also reported $\left(50 \mathrm{~m}^{3}\right)$, as this quantity directly influences the water loop thermal capacity and, thus, represents another relevant parameter of the DSM analysis. This reference represents a trade-off between a restrained electric energy consumption and a specific level of thermal comfort.

Table 5. WLHP baseline configuration

\begin{tabular}{cc}
\hline Parameter & Value \\
\hline Heat recovery set-point temperature, $T_{\mathrm{hr}}\left[{ }^{\circ} \mathrm{C}\right]$ & 20 \\
\hline Auxiliary heater set-point temperature, $T_{\mathrm{ah}}\left[{ }^{\circ} \mathrm{C}\right]$ & 10 \\
\hline Dry cooler set-point temperature $($ minimum $), T_{\mathrm{dc}}\left[{ }^{\circ} \mathrm{C}\right]$ & 20 \\
\hline Water reservoir volume, $V_{\operatorname{tank}}\left[\mathrm{m}^{3}\right]$ & 50 \\
\hline
\end{tabular}

In the following sections, the effect of each parameter reported in Table 5 will be analyzed and discussed in detail, to determine the overall WLHP setup that allows to minimize the yearly electricity cost and, at the same time, to satisfy the HVAC demand with an acceptable degree of flexibility.

\subsection{Water reservoir volume}

The volume of the water tank directly influences the thermal inertia of the water loop and, thus, the annual energy consumption of the overall system.

Figure 5 and Figure 6 show how the electricity use of the various components of the WLHP system changes with a variation of the water tank capacity.

It is possible to note that the heat pumps and the auxiliary heater (Figure 5) are the most demanding elements of the WLHP; in particular, the energy required by the heat pumps decreases with a larger water reservoir, while the heater seems to consume less when the volume of the tank is equal to about $30 \mathrm{~m}^{3}$. This trend could be explained by considering that the EER of the heat pumps takes advantage of cooler water. The auxiliary heater, instead, has its minimum consumption when the volume of the tank is a trade-off between a larger (cooler water) and a smaller (reduced inertia of the system) capacity.

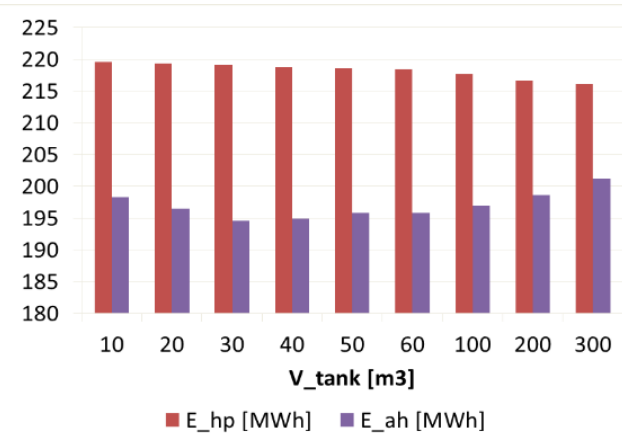

Figure 5. Electric consumption (heat pumps and auxiliary heater) vs. $V_{\mathrm{tank}}$

The dry cooler and the pump (Figure 6) consume less than the heat pumps and the auxiliary heater, and show an opposite trend with the volume of the reservoir: the cooler has a reduced consumption when the storage is large, facilitated by cooler water, while the increase of the pump consumption reflects the trend seen for the auxiliary heater.

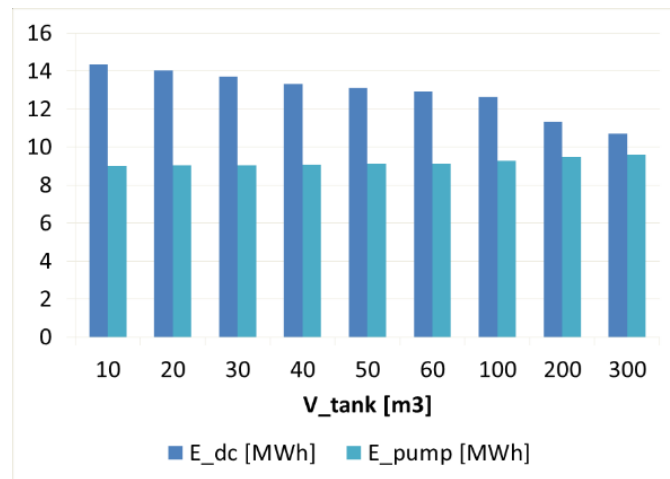

Figure 6. Electric consumption (dry cooler and pump) vs. $V_{\text {tank }}$

Given the remarkable attenuation of the consumption of the heat pumps, it was found that the volume of the storage tank that minimizes the annual cost is equal to about $200 \mathrm{~m}^{3}$. Clearly, this volume size has to be coupled with specific settings of the temperature set-points, as it will be discussed in the following sections.

\subsection{Heat recovery set-point temperature}

The high-pressure heat exchanger of the refrigeration unit is allowed to exchange heat with the water loop only if the temperature of the water does not exceed a too high limit, compatible with the admissible temperature difference approach. In the heating season, it would be desirable that the CRU transfers as much heat as possible to the water loop, in order to keep its temperature acceptable and to avoid the intervention of the auxiliary heater.

For the system considered in the present work, the optimal heat recovery set-point temperature was found to be equal to 
$24{ }^{\circ} \mathrm{C}$ in the heating season.

\subsection{Auxiliary heater set-point temperature}

Along with the heat pumps, the auxiliary heater is the most energy demanding component of the WLHP system. Thus, a correct definition of the set-point temperature that regulates its operation is of great importance in the implementation of a DSM strategy.

In order to guarantee an acceptable degree of flexibility in the operation of the auxiliary heater, the following set-point curve was implemented:

$T_{\mathrm{ah}, i+1}=T_{\mathrm{ah}, i}-k \frac{P U N_{i+1}-P U N_{i}}{\Delta P U N_{\max }}$

where the index $i$ refers to the $i$ th hour of the year and $\triangle P U N_{\max }$ is the maximum variation in an hour of the PUN in 2017. The curve imposed in Eq. (1) allows the auxiliary heater to operate less when the PUN is high, and to operate more when the PUN is low, heating the water and exploiting its thermal inertia during the hours characterized by a higher PUN.

The parameter $k$ is a shape factor that can be adjusted to maximize or minimize the variation of the set-point curve between its limits, which were set equal to 7 and $12{ }^{\circ} \mathrm{C}$ for the auxiliary heater. It was found that Eq. (1) shows a good tracking of the PUN when $k$ is set equal to 100 , as depicted in Figure 7.

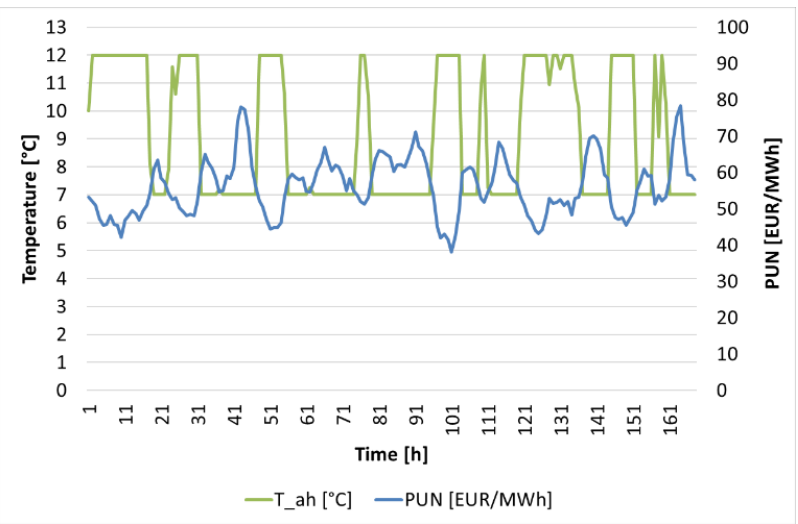

Figure 7. Auxiliary heater set-point temperature and PUN during a typical week

\subsection{Dry cooler set-point temperature}

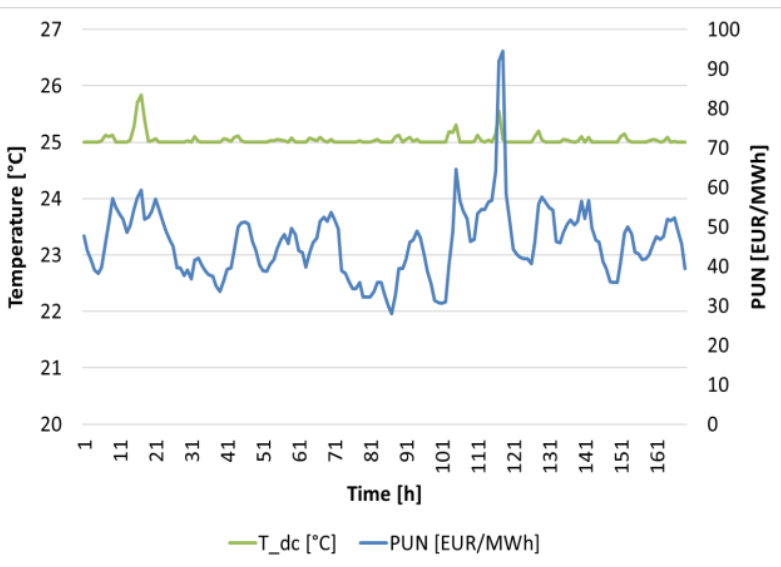

Figure 8. Dry cooler set-point temperature and PUN during a typical week
By default, the dry cooler operates in the cooling season with the aim to keep the water temperature not too higher than the ambient temperature. In order to implement a DSM strategy, the set-point of the cooler was slightly increased to allow an operational flexibility when the PUN is high. A setpoint curve similar to that of the auxiliary heater was adopted:

$T_{\mathrm{dc}, i+1}=T_{\mathrm{dc}, i}+k \frac{P U N_{i+1}-P U N_{i}}{\Delta P U N_{\max }}$

The curve described by Eq. (2) allows the dry cooler to operate less when the PUN is high, and to operate more when the PUN is low. The minimum set-point value allowed to the cooler is $25^{\circ} \mathrm{C}$. Figure 8 shows how the set-point changes with the PUN during a typical week $(k=100)$.

\subsection{Results and comparison with the baseline}

Taking into account the RTP strategies implemented for the set-point temperatures and the new volume of the water tank, the final DSM-based configuration assumes the values reported in Table 6 .

Table 6. WLHP DSM-based configuration

\begin{tabular}{cc}
\hline Parameter & Value \\
\hline Heat recovery set-point temperature, $T_{\mathrm{hr}}\left[{ }^{\circ} \mathrm{C}\right]$ & 24 \\
\hline Auxiliary heater set-point temperature, $T_{\mathrm{ah}}\left[{ }^{\circ} \mathrm{C}\right]$ & $7-12$ \\
\hline Dry cooler set-point temperature $(\operatorname{minimum}), T_{\mathrm{dc}}\left[{ }^{\circ} \mathrm{C}\right]$ & 25 \\
\hline Water reservoir volume, $V_{\mathrm{tank}}\left[\mathrm{m}^{3}\right]$ & 200 \\
\hline
\end{tabular}

Figure 9 shows the electric consumption of the auxiliary heater during a typical winter day, for the baseline and the DSM configuration. When a RTP strategy is adopted, the auxiliary heater is allowed to consume more when the electricity cost is low, and to consume less when the cost is high. Likewise,

Figure 10 depicts the operation of the dry cooler during a typical summer day. In both the configurations, the cooler does not work in the daytime because the water temperature is not excessively higher than the outdoor temperature; in the nighttime, instead, the DSM-based cooler consumes less than the baseline cooler because the imposed RTP set-point curve increases the flexibility of the system.

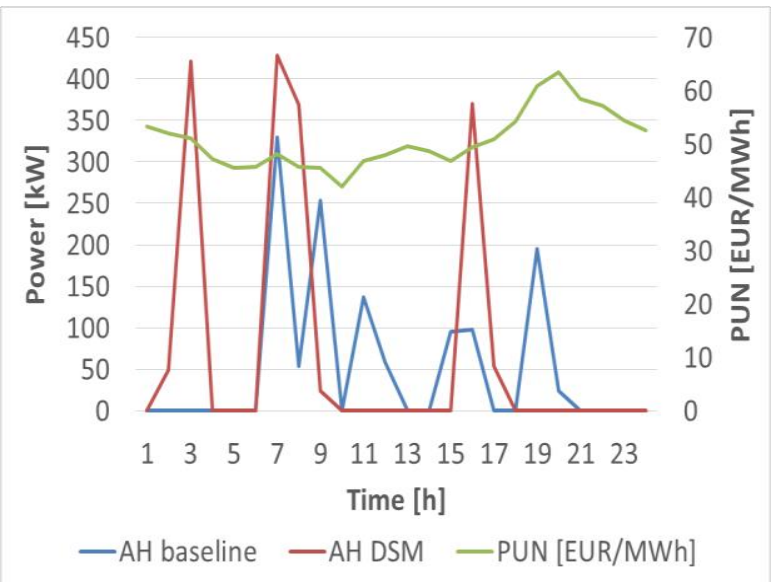

Figure 9. Power consumption of the auxiliary heater during a typical day (baseline and DSM configuration) 
The results of the yearly simulation are provided in Table 7 , Figure 11 and Figure 12. The DSM configuration shows a slightly higher consumption for the heat pumps, which is partly balanced by the reductions registered by the other components of the WLHP system. The dry cooler is the element that mostly benefits of the modified configuration, in particular of the larger volume of the storage tank. The overall consumption $E_{\text {tot }}$ between the two configurations is slightly different, accounting for a difference of $-1.07 \%$ that favors the new setup. Note that $E_{\text {tot }}$ includes all the components of the WLHP system, even the $\mathrm{CO}_{2}$ booster $(319.74 \mathrm{MWh})$ that does not take advantage of the modified setup of the water loop as the high stage pressure is driven by the outdoor temperature.

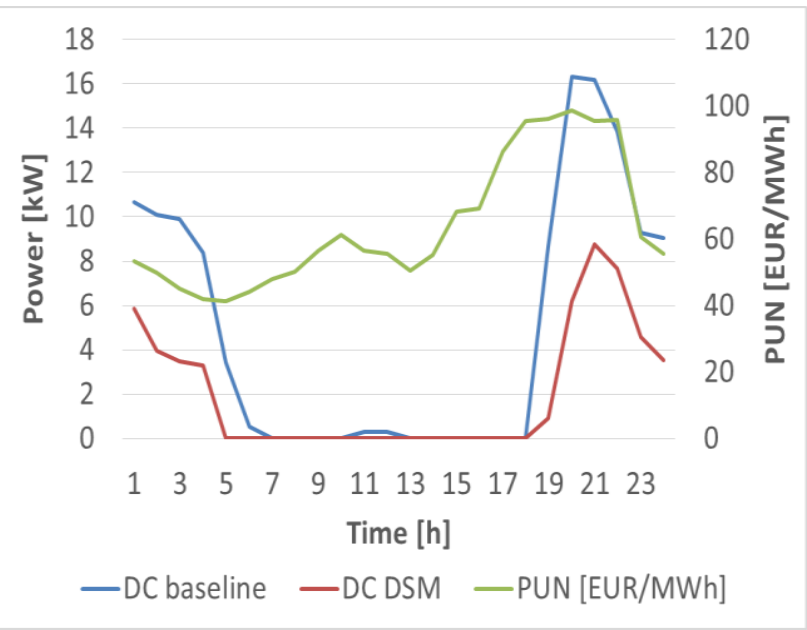

Figure 10. Power consumption of the dry cooler during a typical day (baseline and DSM configuration)

Table 7. Electricity consumptions and cost for the baseline and the DSM configuration

\begin{tabular}{ccc}
\cline { 1 - 1 } Parameter & Baseline & DSM \\
\cline { 1 - 1 }$E_{\mathrm{hp}}[\mathrm{MWh}]$ & 218.58 & 221.67 \\
\cline { 1 - 1 }$E_{\mathrm{dc}}[\mathrm{MWh}]$ & 13.13 & 3.84 \\
\cline { 1 - 1 }$E_{\mathrm{ah}}[\mathrm{MWh}]$ & 195.81 & 194.36 \\
\cline { 1 - 1 }$E_{\mathrm{pump}}[\mathrm{MWh}]$ & 9.11 & 8.67 \\
\cline { 1 - 1 }$\left.E_{\mathrm{tot}} \mathrm{MWh}\right]$ & 756.37 & 748.28 \\
\cline { 1 - 1 }$C_{\mathrm{tot}}[\mathrm{EUR}]$ & $45,585.48$ & $43,602.35$ \\
\hline
\end{tabular}

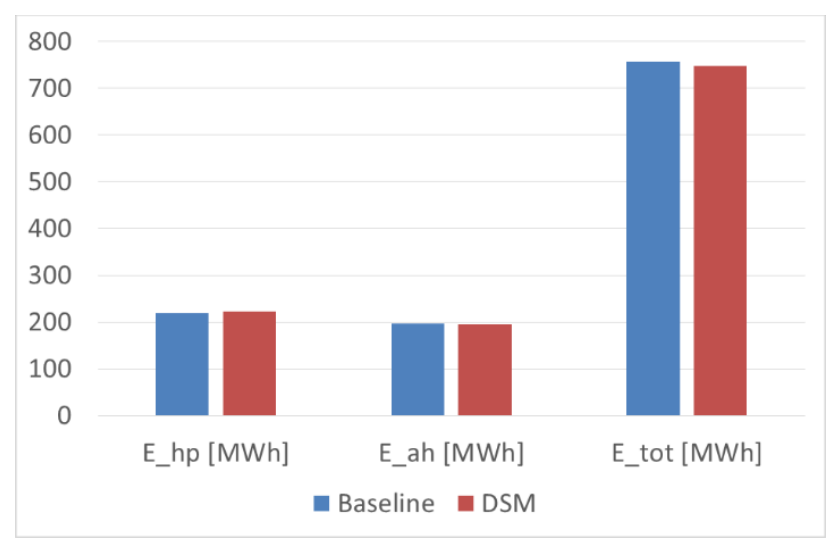

Figure 11. Electric consumption for the baseline and the DSM configuration: heat pumps, auxiliary heater and overall energy

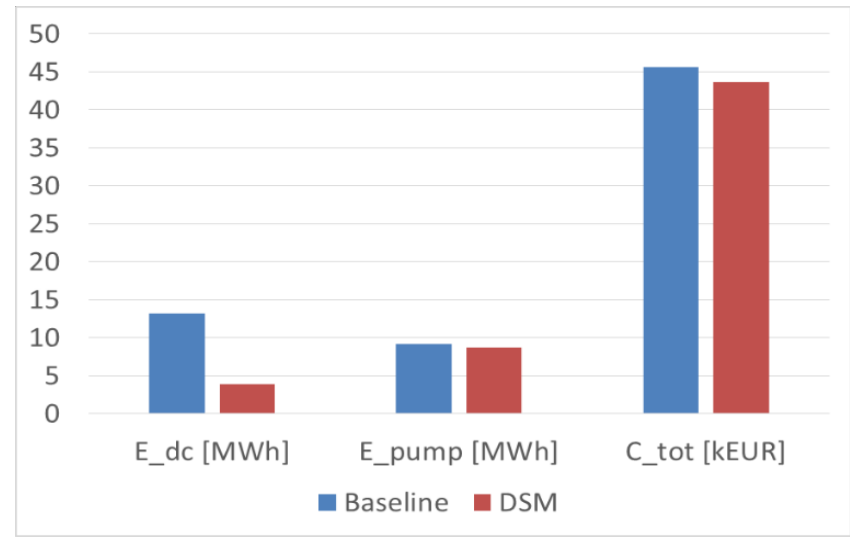

Figure 12. Electric consumption (dry cooler and pump) and overall electricity cost for the baseline and the DSM configuration

The overall electricity cost, instead, is reduced by about 2000 EUR in the DSM configuration, with a relative deviation of $-4.35 \%$. It is worth noting that this cost saving derives only from the implementation of the RTP-based set-point curves and from the new volume of the storage tank; all the other components and control strategies of the system were not modified.

As regards the capital cost for the installation of the larger storage tank, it should be noted that sensible TES devices with hot water as storage medium have investment costs of 0.1-10 EUR/kWh [20]. TES systems for sensible heat are rather cheap because they consist basically of a simple tank for the storage of water and the equipment to charge/discharge [21]. For the storage system of the present study, we considered a specific cost of $100 \mathrm{EUR} / \mathrm{m}^{3}$, which is justified by the reduced amount/quality of thermal insulation required, as the tank is intended to be used in the range of $15-25^{\circ} \mathrm{C}$. Thus, the capital cost for the baseline reservoir of $50 \mathrm{~m}^{3}$ would be 5000 EUR, and its amortization in a period of 20 years would be 250 EUR/year. The same specific cost of $100 \mathrm{EUR} / \mathrm{m}^{3}$ can be applied to the larger storage tank of $200 \mathrm{~m}^{3}$ as there are no strong scale effects for water-based TES systems between 50 and $200 \mathrm{~m}^{3}$ [22], and even for larger installations between 7 and $300 \mathrm{MWh}$ [23]. Thus, the capital cost for the $200 \mathrm{~m}^{3}$ storage tank would be 20,000 EUR, and its 20-year amortization would be $1000 \mathrm{EUR} /$ year, still enough lower than the operational cost saving achieved.

\section{CONCLUSIONS}

A water loop heat pump (WLHP) system coupled to the HVAC and refrigeration utilities of a supermarket was studied according to a demand side management (DSM) approach, specifically adopting a real-time pricing (RTP) strategy.

The analysis showed that it is possible to reduce the annual electricity cost if the set-point temperatures that regulate the operation of the main components of the WLHP system (heat recovery exchanger, auxiliary heater, dry cooler) are adequately modified to match the variations of the national electricity price. Another important parameter of the study is the volume of the water storage tank, that allows to improve the thermal inertia of the overall system if properly oversized. A larger quantity of water, in fact, is able to shift the electricity demand to off-peak hours by means of RTP strategies, providing a larger system flexibility. 
The analysis showed in this work, even if limited to the WLHP system, seemed to provide a quantifiable saving in the electricity cost. However, the DSM approach based on a RTP strategy could be also implemented in the remaining parts of the system under analysis, i.e. the HVAC and the refrigeration utilities. These modifications could provide an additional reduction of the electricity cost.

Finally, it should be noted that a RTP-based DSM strategy could lead not only to an economic saving, but also to a primary energy saving. In fact, if implemented in a consistent number of final users, RTP strategies could directly influence the electricity generation at the source, contributing to integrate more renewable energy sources in the generation mix and to avoid their curtailment by matching the electricity demand with the available production.

\section{ACKNOWLEDGMENT}

This work was supported by the Italian Ministero dell'Istruzione, dell'Università e della Ricerca (MIUR) within the framework of PRIN2015 project "Clean Heating and Cooling Technologies for an Energy Efficient Smart Grid”. Coccia G. would like to express his gratitude to Eng. Enio Ciarrocchi for his useful and detailed support on water thermal storages.

\section{REFERENCES}

[1] Lund PD, Lindergren J, Mikkola J, Salpakari J. (2015). Review of energy system flexibility measures to enable high levels of variable renewable electricity. Renewable and Sustainable Energy 45: 785-807. https://doi.org/10.1016/j.rser.2015.01.057

[2] Faruqui A, Chamberlin JH. (1993). Principles and Practice of Demand-side Management. Palo Alto, CA: Electric Power Research Institute.

[3] Aazami R, Aflaki K, Haghifam MR. (2011). A demand response based solution for LMP management in power markets. Power Energy Syst. 33: 1125-1132. https://doi.org/ 10.1016/j.ijepes.2010.12.018

[4] International Institute of Refrigeration. (2015). The Role of Refrigeration Industry in the Global Economy. 29th Inform. Note on Refrigeration Technology, Paris

[5] Arteconi A, Polonara F. (2017). Demand side management in refrigeration applications. International Journal of Heat and Technology 35(1): 58-63. https://doi.org/10.18280/ijht.35Sp0108

[6] Buonomano A, Calise F, Palombo A. (2012). Building dynamic simulation: Water loop heat pump systems analysis for European climates. Applied Energy 91: 222234. https://doi.org/10.1016/j.apenergy.2011.09.031

[7] Cortella G, Saro O. (2010). Evaluation of energy savings by heat recovery from refrigeration plants in supermarkets. Proc. 1st IIR Conference on Sustainability and the Cold Chain.

[8] Cortella G, D’Agaro P, Saro O, Polzot A. (2014). Modelling integrated HVAC and refrigeration systems in a supermarket. Proc. 3rd IIR International Conference on Sustainability and the Cold Chain.

[9] Arteconi A, Hewitt NJ, Polonara F. (2012). State of the art of thermal storage for demand-side management. Applied $\quad$ Energy $\quad$ 93: 371-389.

https://doi.org/10.1016/j.apenergy.2011.12.045

[10] Polzot A, Dipasquale C, D’Agaro P, Cortella G. (2017). Energy benefit assessment of a water loop heat pump system integrated with a $\mathrm{CO}_{2}$ commercial refrigeration unit. Energy Procedia 123: 36-45. https://doi.org/10.1016/j.egypro.2017.07.282

[11] Klein SA, Beckman WA, Duffie JA et al. (2010). TRNSYS version 17: A transient system simulation program manual. Solar Energy Laboratory, University of Wisconsin, Madison.

[12] Polzot A, D'Agaro P, Gullo P, and Cortella G. (2016). Modelling commercial refrigeration systems coupled with water storage to improve energy efficiency and perform heat recovery. International Journal of Refrigeration 69: 313-323. https://doi.org/10.1016/j.ijrefrig.2016.06.012

[13] Cortella G, D'Agaro P, Franceschi M, Saro O. (2011). Prediction of the energy consumption of a supermarket refrigeration system. Proc. 23rd International Congress of Refrigeration.

[14] Remund J, Lang R, Kunz S. (2014). Meteonorm. Metotest, Bern $(\mathrm{CH})$.

[15] BITZER Software 6. https://www.bitzer.de/websoftware.

[16] Bell IH, Wronski J, Quoilin S, Lemort V. (2014). Pure and pseudo-pure fluid thermophysical property evaluation and the open-source thermophysical property library CoolProp. Industrial \& Engineering Chemistry Research 53(6): 2498-2508. https://doi.org/10.1021/ie4033999

[17] FSS.3 (Frascold selection software) Software. http://www.frascold.it/it/download/software.

[18] Shen B, Ghatikar G, Lei Z, Li J, Wikler G, Martin P. (2014). The role of regulatory reforms, market changes, and technology development to make demand response a viable resource in meeting energy challenges. Applied Energy 130: 814-823. https://doi.org/10.1016/j.apenergy.2013.12.069

[19] Gestore Mercati Energetici. (2018). PUN Index. http://www.mercatoelettrico.org/It/default.aspx.

[20] Miró L, Gasia J, Cabeza LF. (2016). Thermal energy storage (TES) for industrial waste heat (IWH) recovery: A review. Applied Energy 179: 284-301. https://doi.org/10.1016/j.apenergy.2016.06.147

[21] IEA-ESTAP and IRENA. (2013). Thermal Energy Storage - Technology Brief. IEA-ESTAP and IRENA Technology Brief E17.

[22] Riva G, Sotte M, Coccia G. (2015). Accumulo di energia elettrica quale importante strumento per la realizzazione di edifici nZEB. Report Ricerca di Sistema Elettrico, ENEA.

[23] DeForest N, Mendes G, Stadler M, Feng W, Lai J, Marnay C. (2014). Optimal deployment of thermal energy storage under diverse economic and climate conditions. Applied Energy 119: 488-496. https://doi.org/10.1016/j.apenergy.2014.01.047

\section{NOMENCLATURE}

$\mathrm{C}$

COP

CRU

DR

DSM electricity cost, EUR coefficient of performance commercial refrigeration unit demand response demand side management 
electric consumption, MWh

energy efficiency ratio

European Union

heating, ventilation and air conditioning

heat exchanger

shape factor

low temperature

medium temperature

national single price, EUR.MWh ${ }^{-1}$

real time pricing

temperature, ${ }^{\circ} \mathrm{C}$

thermal energy storage storage tank volume, $\mathrm{m} 3$

water loop heat pump

\section{Subscripts}

$\begin{array}{ll}\text { ah } & \text { auxiliary heater } \\ \mathrm{dc} & \text { dry cooler } \\ \mathrm{hr} & \text { heat recovery } \\ \mathrm{hp} & \text { heat pump } \\ \max & \text { maximum } \\ \text { tot } & \text { total }\end{array}$

